\title{
Consumer Behaviour Towards Organic Food in France With a Special Focus on Brittany
}

\author{
Said Al-Hasan ${ }^{1}$, Brychan Thomas ${ }^{2 *}$, Stan Groot Koerkamp ${ }^{1}$
}

\author{
${ }^{1}$ Brest Business School, ESC Bretagne Brest, 2 Av. de Provence, 29200 Brest, France \\ 2University of South Wales, Pontypridd, CF37 1DL, United Kingdom \\ E-mail: said.al-hasan@brest-bs.com; brychan.thomas@gmx.co.uk; stan.koerkamp@brest-bs.com
}

\author{
*Corresponding author details: Professor Brychan Thomas; brychan.thomas@gmx.co.uk
}

\begin{abstract}
This research paper explores French consumer behaviour towards organic food with a particular focus on Brittany. The paper evaluates the demand towards these types of products as well as understanding the main motives for organic food consumption. The research question investigates: 'What are the main drivers in consumer behaviour that influence organic food consumption in Brittany?' This research contributes to the current body of literature by providing up-to-date information with a focus on a specific demographic area that is relevant in the organic food industry in Europe. The results are based on primary research, by conducting a survey among French consumers. Drivers that have the most strength in predicting organic consumption behaviour in Brittany are health benefits, absence of genetically modified organisms (GMOs), environmental impact and price. Variables that have a relatively weak influence are certification warranties, natural appearance of the product and availability. The study provides insight into this growing industry and forms a basis for further research.
\end{abstract}

Keywords: consumer behaviour; organic food; France; Brittany

\section{INTRODUCTION}

This research paper investigates the current situation in the organic food market in France with a focus on consumer behaviour in Brittany. The organic food market has seen continuous growth over the last two decades. Consumer knowledge on these products is increasing and in a world with greater emphasis on the environment and healthy lifestyles this trend is expected to continue for some years. In addition, France is currently one of the largest producers of organic food in Europe. It is therefore imperative to comprehend the reasoning for this shift in consumption and how end consumers can be reached effectively.

Delving deeper into the growing interest in these products and understanding French consumer behaviour towards organic food is the primary aim of this research. The paper evaluates the demand towards these types of products as well as understanding the main motives for organic food consumption. Therefore, the main research question is: 'What are the main drivers in consumer behaviour that influence organic food consumption in Brittany?'

Three objectives have been set to carry out this investigation. The first objective is to outline the current landscape for organic food consumption in France. The second is a better understanding of the relation between lifestyle and organic food consumption. The last is to identify the main motives and restraints of purchasing organic food for French consumers.

This research contributes to the current body of literature by providing up-to-date information with a focus on a specific demographic area that is relevant in the organic food industry in Europe. Seven hypotheses designed by the authors are tested in this research:
- H1: It is expected that consumers mainly buy organic food for health benefits and their concern for environmental implications.

- H2: It is expected that organic labels or nutrition scores on packaging positively influence consumer purchasing behaviour.

- H3: It is expected that price and low availability are the main reasons not to purchase a healthy food option.

- H4: It is expected that people who buy organic food products are also more likely to have a healthy physical lifestyle.

- H5: It is expected that people who buy organic food products are more likely to incorporate environmentally friendly practises in their day-to-day lifestyle.

- H6: It is expected that a higher education level and higher income are positively related to purchase frequency of organic products.

- H7: It is expected that people generally have a positive attitude towards organic food consumption and think that there is a future for organic farming in Brittany.

This research paper is structured by starting with a literature review regarding the organic food landscape in France which can be found in the next section. This is followed by the key research question; a detailed outline of the methodology, the results of the primary research carried out which have been addressed and discussed, and lastly, the paper closes with a conclusion where it provides an answer to the aforementioned main research question. 


\section{LITERATURE REVIEW \\ Background}

Organic food consumption is gaining ground worldwide, as sales are increasing every year with continuous linear growth. In 1999, global sales amounted to a total 15.2 billion dollars whereas a considerable 106 billion dollars in organic food sales were reached in 2019 (Statista, 2021). Although organic farming has been around for thousands of years, in the current food industry this concept is perceived as a relatively new and a growing trend that currently still only represents a relatively small portion of the market.

In the traditional sense of farming there were no inorganic methods available and therefore all food was produced organically. A switch to higher levels of industrial agriculture started after the Industrial Revolution in the United Kingdom with the introduction of more advanced farming machinery and genetic technologies which allowed food producers to reach larger economies of scale. In the early 1900s and particularly after 1940 onwards, a counter reaction known as the organic movement started to make waves as a response to the growing dependency on synthetic fertilizers and pesticides in the agriculture industry. Some of the most influential advocates of organic farming from this movement were the English botanist Sir Albert Howard, American agricultural scientist F.H. King and Austrian philosopher Rudolf Steiner. They all believed in the merits of sustainable organic agriculture and are considered to be pioneers in the industry.

Nowadays, with increasing concern for the environment and personal health, organic food has been getting more and more traction. An increasing number of people have consumed organic food at least once. Nevertheless, many consumers still possess little knowledge of the actual production processes and the essential benefits of organic food consumption.

\section{Definition of Organic Food}

In general terms, food is organic when there is an absence or regulated amount of genetically modified organisms (GMOs) in the food production process. Organic certifications are therefore crucial as it is nearly impossible for the general consumer to identify by themselves whether a certain product contains GMOs. It can therefore be stated that these certifications function as a guarantee of the product being actually organic.

The IFOAM, an acronym for International Federation of Organic Agriculture Movements, is the leading worldwide organisation when it comes to organic food production. It was founded in 1972 by five founding members representing their respective national organic food organisations with the goal of creating a single, coordinated voice for organic agriculture.

The organisation has its roots in France as the initiative was taken by Roland Chevriot, the leader of the French farming organisation, Nature et Progrès, who invited the other founding members to a meeting in Versailles. The other four founding members included:

- Lady Eve Balfour of the Soil Association in Great Britain

- Kjell Arman of the Biodynamic Association in Sweden

- Pauline Raphaely of the Soil Association in South Africa

- Jerome Goldstein of the Rodale Press in the United States of America

Since its establishment, the IFOAM has developed its reach with over 800 affiliates in over 120 countries to the present day. Due to the organisation's strong international reputation, network and connections with numerous international institutions such as among others the United
Nations, the World Health Organization and the International Organization of Standardization (ISO) it is valuable to consider the definition of organic food given by the IFOAM as a base reference in the context of this research:

"Organic Agriculture is a production system that sustains the health of soils, ecosystems, and people. It relies on ecological processes, biodiversity and cycles adapted to local conditions, rather than the use of inputs with adverse effects. Organic Agriculture combines tradition, innovation, and science to benefit the shared environment and promote fair relationships and good quality of life for all involved." (ISO)

From this definition it can be stated that organic food production goes much further than the physical product itself. It concentrates on improving and maintaining the health of communities, individuals and ecosystems. This includes efforts in recycling, fair value or remuneration for farmers, processors, distributors and consumers involved in the supply chain. Furthermore, it places an emphasis on continuous scientific innovation in terms of technology and practices to keep up with growing expectations and competitiveness in the industry.

Organic food exists in many product groups such as fruits, vegetables, milk, eggs, herbs, meat, beverages and even alcoholic drinks amongst others. In the context of this research all organically processed foods are considered regardless of specific product groups.

\section{Organic Food in France}

France plays a significant role in the organic food industry. Globally it was the third largest consumption market for organic products in 2019, only behind the United States and Germany, with a total value of $€ 11.93$ billion (Agence BIO, 2020). The growth of this consumption market in France is only emphasised by the $13.5 \%$ increase in value compared with the previous year. Furthermore, the value of the organic consumption market was €6.4 billion in 2015. This means that the value of the total market has almost doubled in four years (Agence BIO, 2020).

\section{Share Of Organic Food Consumption Of European Total}

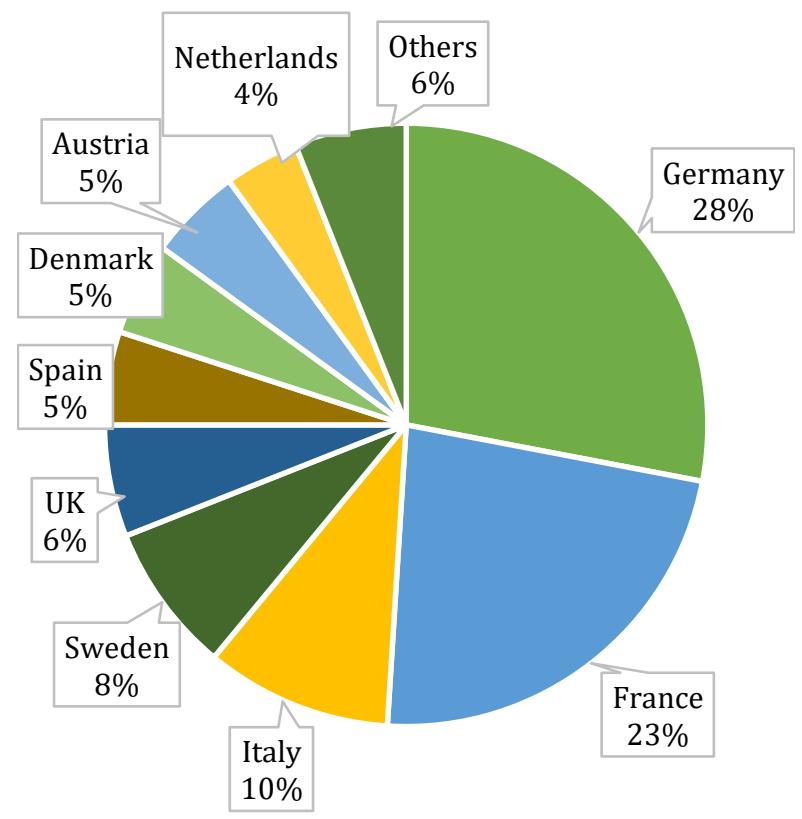

FIGURE 1: Share of Organic Food Consumption of European Total In 2019 (Source: Agence BIO) 
In the European context, France is good for $23 \%$ of its total organic food consumption (Figure 1) (Agence BIO, 2020). Only Germany boasts a higher share. With a population of more than 68 million people divided over 28 million households France is one of the largest food markets in Europe. However, organic food penetration is higher than other countries with a similar population size such as the United Kingdom and Italy.

\section{Organic Food in Brittany}

Brittany is located in the far west of France and consists of four departments being Côtes-d'Armor, Finistère, Ille-etVillaine and Morbihan. The population of the region as a whole is estimated to be around 3.3 million people. Brittany has a long history of agriculture and is characterised by its mild climate with soft relief and regular rain fall. The conventional agrifood industry in Brittany is mainly oriented towards the meat and dairy industry.
In addition, Brittany is the most important fishing region in France as it accounts for almost half of national fishing sales. It is also the first region in terms of shellfish farming areas.

In 2016, Brittany ranked first among all regions with regards to animal production with a national share of $22 \%$ of the total value. More specifically, Brittany accounts for $56 \%$ of the production of pigs, $21 \%$ of calves, $33 \%$ of broilers, $42 \%$ of eggs for consumption and $22 \%$ of milk. Furthermore, it represents $40 \%$ of national tonnages for animal slaughter. Despite its strong output on animal and dairy production, Brittany also amounts to a large share of vegetable farming. In fact, it ranks as the third French region for vegetable production. Brittany has the highest national output of cauliflowers (84\%), artichokes and shallots $(80 \%)$ and more than half of spinach and a third of tomatoes (Direction Régionale de l'Alimentation, de 'Agriculture et de la Forêt, 2018).

TABLE 1: Distribution of surface of organic farm land (Source: based on data-sets of Agence BIO)

\begin{tabular}{r|c|c|}
\cline { 2 - 3 } & Certified organic surface 2019 & Evol. / 18 \\
\cline { 2 - 3 } OCCITANIE & 383777 & $11,79 \%$ \\
NOUVELLE-AQUITAINE & 226161 & $16,00 \%$ \\
PAYS DE LA LOIRE & 206054 & $15,28 \%$ \\
BOURGOGNE-FRANCHE-COMTE & 162576 & $13,35 \%$ \\
PROVENCE-ALPES-COTE D'AZUR & 135761 & $15,87 \%$ \\
GRAND-EST & 131196 & $13,44 \%$ \\
BRETAGNE & 121955 & $13,20 \%$ \\
NORMANDIE & 97610 & $13,21 \%$ \\
HAUTS-DE-FRANCE & 81592 & $12,27 \%$ \\
CORSE & 56091 & $8,73 \%$ \\
ILE-DE-FRANCE & 31568 & $16,32 \%$ \\
OUTRE-MER & 21230 & $37,16 \%$ \\
\cline { 2 - 3 } & 14678 & $15,01 \%$ \\
\end{tabular}

France is composed of 13 regions plus its overseas territories. Brittany ranks as number eight in terms of certified organic production surface (Table 1). It is clear that across all departments there is a huge growth in conversion to more and more organic farming. Excluding the region Centre-Val de Loire all other departments have seen a growth percentage of over $10 \%$ compared to the previous year with Corsica even reaching a massive $37.16 \%$ increase. This only highlights the growth potential and increasing foothold that organic food has on the agriculture industry in France. In 2019, Brittany had 3.347 organic farms which was an increase of $7.97 \%$ compared to the year before.
From all departments this was the lowest percentage increase, however Brittany still ranks sixth in terms of number of organic farms in France in 2019 (Agence BIO, 2020).

In terms of organic surface exploited, agriculture production is fairly evenly distributed throughout the four departments of the region (Table 2). Organic forage represents the vast majority of the overall organic surface utilised. Subsequently, large organic crops and fruits and vegetables also make up a considerable portion of the total. This is in line with conventional agriculture in Brittany where these three domains are most prevalent as well.

TABLE 2: Composition of organic farming in Brittany (Source: based on data-sets of Agence BIO)

\begin{tabular}{|r|c|c|c|c|c|c|c|}
\cline { 2 - 8 } & $\begin{array}{c}\text { Organic } \\
\text { forage } \\
\text { surfaces }\end{array}$ & $\begin{array}{c}\text { Large } \\
\text { organic } \\
\text { crops }\end{array}$ & $\begin{array}{c}\text { Organic } \\
\text { fruits and } \\
\text { vegetables }\end{array}$ & $\begin{array}{c}\text { Organic } \\
\text { wine }\end{array}$ & $\begin{array}{c}\text { PPAM } \\
\text { Bio }\end{array}$ & $\begin{array}{c}\text { Other } \\
\text { Organic } \\
\text { Surfaces }\end{array}$ & Total \\
\cline { 2 - 8 } COTES-D'ARMOR & 17077,3124 & 4447,61 & 2127,2643 & 0 & 12,56 & 530,09 & 24194,8367 \\
\cline { 2 - 9 } FINISTERE & 15412,026 & 3111,25 & 2550,9924 & 1,17 & 36,828 & 544,629 & 21656,8954 \\
\cline { 2 - 9 } ILLE-ET-VILAINE & 21854,6226 & 4380,77 & 1248,3524 & 0,48 & 8,19 & 227,3326 & 27719,7476 \\
\cline { 2 - 9 } MORBIHAN & 18769,1798 & 3847,04 & 859,331 & 0,05 & 57,81 & 504,8078 & 24038,2186 \\
\cline { 2 - 9 } Total & 73113,1408 & 15786,67 & 6785,9401 & 1,7 & 115,388 & 1806,8594 & 97609,6983 \\
\cline { 2 - 9 } Percentage of total & $74,90 \%$ & $16,17 \%$ & $6,95 \%$ & $0,00 \%$ & $0,12 \%$ & $1,85 \%$ & $100 \%$ \\
\cline { 2 - 8 } & & & & & & &
\end{tabular}


Maigné, Monier and Poméon (2017) suggest that there is potentially a positive link between living in a French department with a high percentage of organic agriculture and the consumption of organic products. This conclusion was reached by comparing the distribution of national market share for a selection of organic products and the share of agricultural surface used for organic farming. This seems particularly true for the north-west and south-east areas of France where both consumption and organic agriculture are relatively high. Although there are some exceptions to this theory such as the Île-de-France area where organic farming is low and organic consumption levels are above average.

There are two options for boosting the growth of organic agriculture, either taking the pull approach or the push approach. The pull approach is built on the idea that market growth is carried by consumer demand that pulls these products through the supply chain. Therefore, authorities would have to install policies that stimulate this demand which in turn will force producers to increase their production output for organic food. On the contrary, with the push approach the products are pushed through the supply chain starting from the producers with production levels based on historical data and forecasted demand. It seeks to promote organic products by pushing them onto consumers and therefore increase sales.
The two strategies can possibly be used in conjunction with each other if they are well calibrated (Lampkin, 1996).

\section{Profile of Organic Food Consumers}

In addition to product attributes to analyse consumer behaviour it is essential to look at characteristics of consumers themselves according to socio-economic factors. These socio-economic characteristics can change the ranking of purchase motives. For instance, a seventyyear-old retired man might not hold the same reasons to purchase organic food products than a twenty-five-yearold female student. Therefore, segmentation is not only made on demographic characteristics, in addition emphasising benefits pursued is considered as an important aspect in segmenting organic food consumers (Gad Mohsen and Dacko, 2013).

Organic products are increasingly aimed at broader groups of consumers in a variety of consumer groups that each possesses their own worldview and value systems. Furthermore, the frequency of purchases should be taken into account. With an increasing assortment in stores the distinction between exclusive organic consumers and consistent non-buyers is not as defined as it was previously the case.

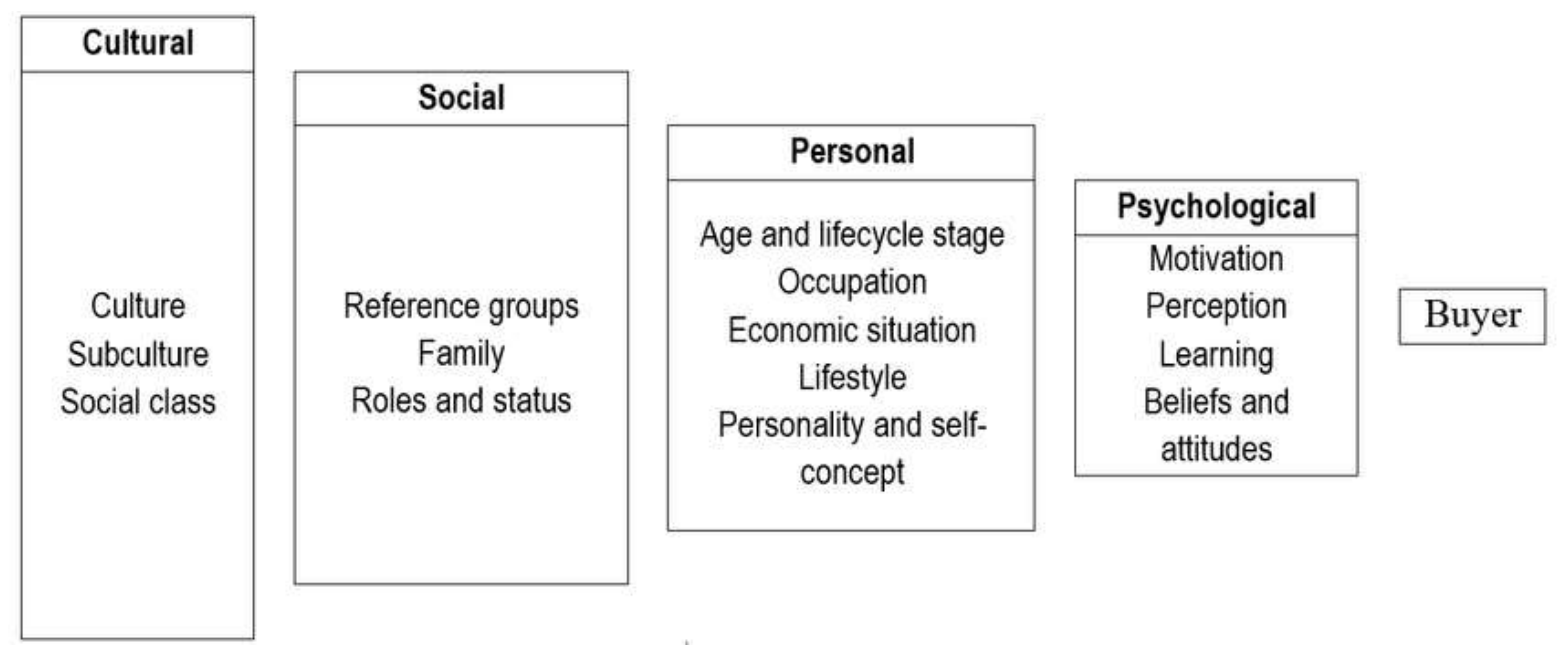

FIGURE 2: Factors influencing consumer behaviour (Kotler et al., 2005)

The model by Kotler et al. (2005) (Figure 2) shows the inter-relation between cultural, social, personal and psychological factors that ultimately lead to the purchase decision. All four characteristics together will attempt to describe consumer groups by analysing their place in society and personal motivations. These are largely not aspects that can be controlled by marketing efforts from parties involved in the organic food industry. However, they should be taken into account when attempting to stimulate demand among consumers.

\section{Cultural}

Cultural characteristics refer to a set of values, perceptions and behaviours instilled in a person which are largely learned from family, friends, society and institutions. Furthermore, purchasing behaviour can be related to how a person is perceived in terms of social status. Culture is largely seen as country-bound but even within countries there exist various sub-cultures. To further demonstrate the influence a culture can, have, Götze (2019) found that people in the German speaking region of Switzerland are more inclined to consume organic food than their French speaking counterparts. Furthermore, there were little differences found between the French speaking region and the Italian speaking part of Switzerland. Switzerland is a particularly interesting case to analyse as it is one of the few countries in Europe with such a specific divide between languages and cultures living under one constitution. This negates many variables that would be present between comparing consumption between countries directly.

In a country such as Switzerland the cultural component among regions in the decision-making process is therefore probably more pronounced than France. Although this does not mean that there might not exist differences between French regions in terms of values, perceptions and behaviours or even within regions among various cultural groups. Furthermore, in the same study it was demonstrated that among all regions in Switzerland urban households are more likely to purchase organic products than those living in rural locations (Götze, 2019).

Several beneficial attributes of organic food such as environmental impact and fitness and health could be social aspects that are more valued in one society than another and being conscious of them in purchase behaviour could even provide a consumer with a certain status. 
For instance, organic food was seen by British consumers as a way to acquire societal status and fulfil personal aspirations (Shafie and Rennie, 2012). It should be taken into account that not all cultural values in terms of what is valued in life are by definition universal.

In addition, it is possible for cultural shifts to take place within a society. For instance, if health consciousness is being increasingly valued and stimulated in a society then consumers might become increasingly aware of their food in-take. Similarly, if more emphasis is given to climate change then people might be more inclined to make a conscious effort to reduce their personal carbon foot print by for instance recycling their waste and purchasing an electric car instead of a gasoline driven vehicle.

Generally, in almost every society there exists some type of social class structure based on groups that share similar socio-economic variables such as occupation and education. A society is commonly divided into upper, middle and lower class. These categories are solely made to classify common values, interests and behaviours among a group of people.

Pierre Bourdieu (1979) studied the tastes, leisure activities and eating habits within the French classes. Bourdieu (1979) indicated that the differences in eating habits among social classes were mainly down to income differences. For instance, lower classes are more likely to purchase fattening, more difficult to digest and most importantly cheaper foods such as pasta, potatoes, beans, bacon and pork. Eating these foods, furthermore, stimulate strength of the body which aids in occupations that include heavy physical labour. On the other hand, the upper-class values more non-fattening foods such as beef, veal and lamb as well as fruits and vegetables. Their diet is defined by lighter, more refined food that is tasty, health promoting and does not make a person fat. Food consumption can therefore become a symbolic reference to a social class (Bourdieu, 1979).

\section{Social}

People are often influenced by those around them in their behaviour, wants and needs. The social environment, including family, friends, peers and society, therefore has a significant impact on consumer decision making. In line with the cultural aspect, people compare themselves to their peers and try to attain social status by achieving or doing what is valued in society.

A distinction can be made between various groups that can influence a consumer. The primary group is the closest circle of people that a person regularly interacts with that consist of for instance family, friends and co-workers. Secondly, the secondary group consists of organisations or associations that the consumer might be part of. These are typically identified by less frequent interaction and more formal communication than the primary group. Lastly, there are the reference groups. These reference groups might be people that the consumer might not have direct contact with but feels like he or she can identify themselves with. These could for instance be sport stars, musicians or any other public figure that the consumer might take inspiration from.

Women are more likely to purchase organic food products as they are often the primary grocery shoppers in the household and more aware of nutrition and food safety (Yiridoe et al., 2005). Furthermore, it is indicated that having children increases organic purchases of a household (Ozguven, 2012). This is nuanced by Wier et al. (2008), who suggest that having one or two children in the household increases the purchasing frequency while having three or more children will decrease the amount of organic purchases.
In addition, the same research suggests that in particular having younger children has a positive effect on organic food purchases while having older children has a negative impact. It is hypothesised that parents become more health conscious and are concerned by food safety in particular for babies and children of a young age. Moreover, having more than three children or children of an older age might lead to larger financial expenditures. This leaves a strain on food purchases with a higher price premium such as organic products. This leads back to the relationship between price and advantageous purchase attributes such as attained health benefits.

In addition, older children can also influence the purchase decisions by influencing the parents with their preferences. Older children are also able to express their desires more directly verbally to their parents than younger children and babies. Family and direct social environment strongly influence consumption; moreover, in one household it is possible to have multiple decision makers. Perhaps the family life cycle could be a better predictor for consumer behaviour than other demographic characteristics such as age.

\section{Personal}

Personal factors refer to the influence of profession, income, life phase and lifestyle of a consumer on their purchase behaviour. Preferences and consumption patterns can change over a lifetime and are often the result of these factors as well as the influence from family and friends. There are conflicting findings regarding the connection between age and organic food consumption. It is suggested that middle-aged households have the highest inclination to purchase organic (Wier et al., 2008), however it is also reported that consumers under the age of 30 are the most likely consumer group (Dettmann and Dimitri, 2010; Magnusson et al., 2001). As it is still a relatively new and growing market it might be attractive to young consumers who might be more in tune with current world issues such as the environment and health consciousness. On the other hand, with the price premium that most organic products have this might impede them to make actual purchases as they still tend to have relatively low incomes. Contrarily, it might be an interesting option for older consumers looking for products of high quality with slightly higher financial capacities. Income has a positive effect on organic purchases (Dettmann and Dimitri, 2010) whereas others indicate no correlation (Li et al., 2007; Zepeda and Li, 2007). In theory it would make sense for consumers with a higher income to have higher expenditures towards organic food as the price premium might be a smaller financial burden, however research is not conclusive whether this is actually the case in practise.

Multiple studies have found a strong relation between education and consumption with the higher the academic level the more likely a person is to consume organic food products (Wier et al., 2008; Dettmann and Dimitri, 2010; Dimitri and Dettmann, 2012). Furthermore, households living in urban areas spend a higher share of their food budget on organic food than those in rural areas (Zhang et al., 2006).

Another potential interesting link that can be made is between consumption and the lifestyle of a consumer. This is to see whether benefits sought in organic food products such as health benefits and the protection of the environment are also evident in other life choices and consumer patterns. For instance, in theory a person who seeks health benefits from organic food would probably be more likely not to smoke cigarettes. 
Similarly, a person who is concerned about climate change might next to consuming organic food also be more likely to take public transport more often. However, there is not much conclusive research available on this relationship yet in the domain of organic food to segment consumers according to their lifestyle.

The COVID-19 pandemic derailed daily routines and lifestyle patterns of many consumers. This was also evident in food consumption patterns where French consumers were much more influenced by their mood in their food intake choices. Particularly boredom and emptiness were two main drivers for this change. Furthermore, emphasis on weight control and health were other aspects influencing food choices whereas convenience and price became less decisive factors (Marty, de Lauzon-Guillain, Labesse and Nicklaus, 2021).

\section{Psychological}

This element refers to the motivation, perception and beliefs and attitudes of a consumer. These are heavily linked with the purchase attributes that might be seen as a benefit or a disadvantage of buying organic. A motivation for purchasing food could be simply to still hunger. However, the purchasing decision is much more complex than that. Supermarket consumers have a wide selection of choice for food products and there are other benefits sought than just eating for survival. This is where the purchase attributes come into play and what might be important for one consumer as a motivation to buy might not necessarily be the same for another.

Motivation can also change over time or with certain events. For instance, during the COVID-19 pandemic people started preparing more meals at home instead of eating out and their eating patterns changed. This might consequently have an effect on their weekly grocery shopping and the products that they purchase. During this period, some people put extra consciousness on improving their physical health while others with a disruption of their daily routines started living an unhealthier lifestyle than they did previously.

Another factor of a purchase motivation would be belonging, meaning belonging to a group that the consumer would like to identify themselves with. An organic consumer might for instance want to identify themselves as a person who places importance on the protection of the environment or who is health conscious. These are related to the personal values of an individual person.

\section{Buyer}

The buyer is a combination of the cultural, social, personal and psychological elements together. It helps to identify who the consumer is and what motivates them. It aims to answer whether the consumer base of organic food is a homogenous group that shares the same characteristics and motivations or if there are different segments within. The only conclusive socio-demographic factor that has a positive effect on organic consumption is education. This in turn could work further into income as well as people with an above average education will also tend to reach an above average income. In terms of the purchase attributes, the consumer will probably not choose organic over conventional food products for just one of the advantages but rather a combination of attributes. It seems that particularly health benefits and environmental impact are valued aspects in organic products.

The increased availability for consumers is helping to grow the organic food industry. However, it is essential to keep communicating the tangible benefits of these products clearly with appropriate promotion that engages with the emotions of consumers to further encourage organic consumption (Latacz-Lohmann and Foster, 1997).
In conclusion, the organic movement saw its infancy in the early 1900s and really started to take shape after 1940 . Organic agriculture and organic food products can be defined as much more than offering just a physical product for consumption. It aims to protect the environment and maintain the well-being of people. Organic food products exist across many product groups that include both fresh and shelf-stable products. In France, the organic food sector has seen tremendous growth in recent years and has developed itself as the third largest organic consumption market worldwide. Some 55 percent of organic food products in France are sold through mass retail which includes hypermarkets, supermarkets, convenience stores, e-commerce and hard discounters. In comparison to the rest of Europe, France has the second highest number of organic farms and also the second highest total surface of organic cultivated farmland. For farmers, to convert their land to organic farmland can be attractive due to the higher price premiums. However, there are also variable costs involved that can differ depending on individual cases. A significant amount of organic production is exported, mainly to other European Union member states. Furthermore, the COVID-19 pandemic did not de-accelerate the rapid growth of the organic sector in France. When focusing on Brittany, production is mainly focused on the production of animals, dairy products and vegetables. Brittany ranks as the sixth region in terms of number of organic farms in 2019, despite having the lowest growth percentage of new organic farms in France. The European Union is putting increasing efforts in developing the organic industry which is evident from their 'Farm to Fork' strategic plan which involves objectives on a European level to reach $25 \%$ of total farmland to be organic by 2030. The Farm to Fork plan is part of the European Green Deal which aims to make Europe the first climate neutral continent by 2050 . There are multiple motives or drawbacks from purchasing organic food products. These attributes can be divided into private and public motives. Private attributes refer to direct advantages that the consumer experiences and that cannot be shared. On the contrary, public attributes have a more altruistic underlying motive that contributes to the greater good of the planet and mankind. Purchase motives and drawbacks examined include: absence of GMOs, animal welfare, availability, certification warranty (organic logos), environmental impact, expectation of a better taste, fair remuneration for farmers, health benefits, more natural appearance, nutritional value, origin and price. The general consensus in the literature available is that especially health benefits, environmental impact and price have a strong influence on purchasing behaviour. In addition, socio-economic factors should be considered in relation to consumption patterns which consist of characteristics such as age, income, family status, lifestyle and culture which each have varying influences on organic food consumption.

\section{METHODOLOGY}

For this research it was decided to take a positivist approach with regards to information collection by gathering quantitative data from primary sources. This approach has been favoured by the authors as it suits the aim of the research and corresponds with effectively testing the pre-established hypotheses. Using quantitative data will provide clearer patterns regarding the motives of purchasing organic food as well as exploring if there is a link between the lifestyle of consumers and their organic purchasing behaviour. There could be multiple stances on the reasons that influence the decision whether to buy organic food products as there are many factors that differentiate consumers such as demographic characteristics, consumer attitudes, motives and lifestyles. 
Furthermore, to better understand the possible consumer profiles and their relevance, it requires an objective mindset to discover quantifiable results from a subjective consumer experience.

The aim of the research is to understand French consumer behaviour towards organic food and delve deeper into the purchase motivations that drive this. The rule, the interest of French consumers in organic products has positively increased, is known and the effect is that the sales of organic purchases have increased. The objective is to confirm or dismiss the potential drivers. Therefore, abduction is utilised in this research.

The decision was made in the epistemology to follow a positivist approach. It has therefore been determined to concentrate on acquiring information by means of quantitative data gathering methods for the primary research. Through this method, it will be attempted to make generalisations regarding consumer profiles, purchasing patterns and purchasing motives. The primary data collection method used in this research will be surveys as it is in line with the positivist approach adopted in the epistemology desiring objective quantitative data. This research method is also thought to accommodate answering the main question of the study most efficiently and objectively. The decision not to use interviews and focus groups is that these research methods lead to descriptive qualitative information and as aforementioned the positivist stance is taken in the epistemology which essentially requires quantitative information collection.

This study utilises a cross-sectional research where the consumer behaviour of French consumers is explored at a single period in time between June 2021 and December 2021.
The advantage of using a cross-sectional research is that it provides an overview of multiple variables at a certain moment of time and can therefore approve or disapprove assumptions made in the hypotheses. Furthermore, it does open up the opportunity for future research to perform similar research and use this study as a base for contrasting data at different moments in time or across countries. This in turn can potentially show an evolution in consumer behaviour or demonstrate differences in culture.

Primary data has been gathered by means of a survey among French consumers. The secondary data in the literature review supports the primary research by providing context to the primary research and as a reference for the results gathered. The results can therefore be compared to the existing research and potentially add as a reference to the current body of literature available on the subject. It is attempted to provide more insight in the purchasing behaviour of a specific group of people, being French consumers, by exploring their purchase motives. The target group of the research are consumers in Brittany who are 18 years or older. Consumers younger than this age are not included as they normally are not one of the main decision makers in the purchase process in their household. The data has been collected through the means of online surveys distributed among consumers living in Brittany, with respondents residing in the department of Finistère. The choice for conducting online surveys was made for the ease of use for participants, possibilities for wider and faster distribution as well as the efficiency of analysing the data. The composition of demographic data of the respondents is presented in Table 3.

TABLE 3: Demographics of survey respondents

\begin{tabular}{|c|c|c|c|}
\hline Classification variable & Modality & & \\
\hline \multirow{5}{*}{ Age } & 18 - 30 years old & 70 & \multirow{5}{*}{84} \\
\hline & $31-43$ years old & 3 & \\
\hline & $44-56$ years old & 7 & \\
\hline & $57-69$ years old & 4 & \\
\hline & 70 years or older & - & \\
\hline \multirow{2}{*}{ Gender } & Male & 39 & \multirow{2}{*}{84} \\
\hline & Female & 45 & \\
\hline \multirow{5}{*}{ Academic level } & Lycée & 3 & \multirow{5}{*}{84} \\
\hline & $\mathrm{Bac}+2$ (BTS, IUT ...) & 7 & \\
\hline & Licence & 15 & \\
\hline & Master & 57 & \\
\hline & Doctorat & 2 & \\
\hline \multirow{10}{*}{ Income } & Not applicable & 19 & \multirow{10}{*}{84} \\
\hline & Less than $€ 1.000$ & 19 & \\
\hline & Between $€ 1.000$ and $€ 1.500$ & 15 & \\
\hline & Between $€ 1.500$ and $€ 2.000$ & 11 & \\
\hline & Between $€ 2.000$ and $€ 2.500$ & 7 & \\
\hline & Between $€ 2.500$ and $€ 3.000$ & 3 & \\
\hline & Between $€ 3.000$ and $€ 5.000$ & 7 & \\
\hline & Between $€ 5.000$ and $€ 8.000$ & 2 & \\
\hline & $€ 8.000$ or more & - & \\
\hline & I do not know & 1 & \\
\hline
\end{tabular}

The content of the survey has been created by dividing it into four blocks. The first block of questions consists of demographics including age, income, gender and education. This is followed by the second block of questions related to consumption frequency and lifestyle choices in other areas of life related to similar benefits that organic food products can provide. Thirdly, respondents were asked to rank from a list of motives which they find the most important in relation to organic food purchases.
In the same block respondents were also asked for reasons why they would not purchase organic products or in other words what would incentivise them to increase their consumption. Lastly, respondents were asked to respond to a series of statements related to various aspects of organic consumption in agriculture in the Brittany region and rate their level of agreement through a Likert scale. It is attempted with this survey to obtain a full overview of consumer behaviour patterns in Brittany by highlighting various aspects such as demographics, lifestyle and purchase motives so that they can be contrasted against each other. 


\section{RESULTS}

This section aims to respond to the hypotheses and ultimately provide an answer to the main research question. The results are based on a survey conducted among 84 participants in Brittany, France. The main aim of the study is to understand French consumer behaviour towards organic food and delve deeper into the purchase motivations that drive this. The following sub sections provide the main results of the research regarding the main drivers in consumer behaviour that influence organic food consumption in Brittany.

\section{1: PRODUCT ATTRIBUTES FRENCH CONSUMERS VALUE IN THE PURCHASE OF ORGANIC FOOD PRODUCTS}

To determine the product attributes that consumers value most in organic food products respondents were asked to rank 10 pre-determined product attributes from a scale of
1 to 10 , with 1 being the most important attribute and 10 being the least important for them personally.

The advantage of ranking the attributes, instead of for instance a Likert scale, is that it forces respondents to discriminate between them and it therefore exhibits a clearer preference for one attribute or another.

Response frequency of purchase motivations shows the response frequency for each attribute with their rank as well as the percentual rates for each individual attribute and their rank. Furthermore, a total score has been attributed to each product attribute by multiplying the response frequency with Rank 1 by a score of 10, for Rank 2 by a score of 9 , continuing to Rank 10 with a score of 1 . Adding up all these scores has resulted in a total score for each attribute displayed in Figure 3.

\section{I buy organic food products because of...}

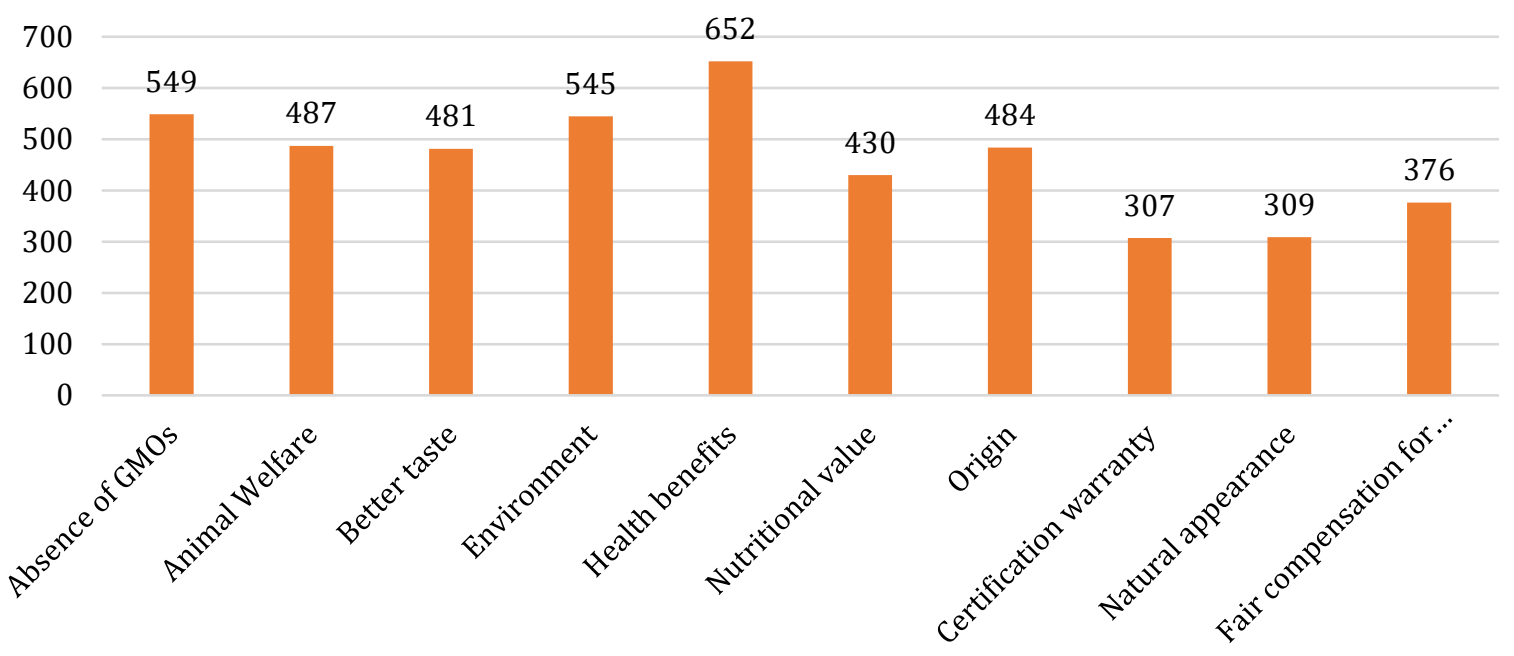

FIGURE 3: Total scores for motives for purchasing organic food

The attributes that were chosen among respondents as most important in organic food products and were ranked first were health benefits (25\%), absence of GMOs $(21.4 \%)$ environment (11.9\%), animal welfare $(10.7 \%)$ and better taste (9.5\%).This is congruent with the ranking according to the overall scores given in Figure 3, with the exception of the attribute 'origin' that overtakes the expectation of better taste for fifth place. Attributes that were seen as least important consist of certification warranties, natural appearance and fair compensation for farmers. Similar research conducted by Nunes, Madureira and Veiga (2021) among Portuguese respondents shows comparable results with health benefits, absence of GMOs and environmental impact as the most valued attributes in the same order and organic logos, appearance and availability as relatively weak influences.

\section{2: THE MAIN REASONS FOR FRENCH CONSUMERS NOT TO PURCHASE ORGANIC FOOD}

Contrarily to drivers of the organic food market, it is imperative to analyse potential obstacles and identify reasons that refrain consumers from purchasing these products which could limit potential growth.

Similar to the products' attributes that were favourable for purchasing organic food, respondents were presented with ten potential obstacles that if taken away would stimulate their organic food consumption. Again, respondents were asked to rank these reasons from Rank 1, being the most important, to Rank 10 being the least important for them. Consequently, reasons for not purchasing organic food can be deduced from these statements.
Response frequency of attributes that would stimulate organic food purchases.

In the total scores and looking at the response percentages it is evident which attributes are the main obstacles for purchasing organic. The four attributes that stand out can be divided into two categories being related to price and other to consumer trust. Some $35.7 \%$ of respondents put having a higher income as their first choice of factor that would stimulate opting for organic, followed by product prices being lower with $22.6 \%$. This means that $58.3 \%$ of respondents put a cost related reason as their main obstacle for not choosing an organic option more often, whether it comes from an income point of view or a product price stand point. Furthermore, a lack of trust in products actually being organic $(16.7 \%)$ and lack of trust in organic certification logos $(7.1 \%)$ were expressed as another significant concern. Together, it represents $23.8 \%$ of respondents who ranked a lack of trust as number one. In addition, 30.9\% of respondents ranked either of these two reasons as the second most important hurdle not to go for an organic option.

\section{3: THE RELATION BETWEEN CONSUMER LIFESTYLE AND THE PURCHASE OF ORGANIC FOOD}

Another interesting relation to explore is the potential link between the lifestyle of consumers and their food consumption behaviour. It looks to investigate whether benefits sought such as those related to the improvement of personal health or the protection of the environment are also reflected in other areas of life. This could contribute to creating a more complete consumer profile. 
A comparison has been made between the organic food consumption frequency among respondents between smokers and non-smokers. It can be concluded that nonsmokers are more likely to consume organic food more frequently than smokers. No smokers indicated that they consume organic food on a daily basis whereas $23.44 \%$ of non-smoker respondents do put themselves in the category of daily consumers. Even the difference of consumption on a weekly basis is fairly high with only $15 \%$ of smokers eating organic food at least once a week opposed to $34.38 \%$ of non-smokers. Personal health benefits were indicated as the most important reason for consuming organic food and this is the first indication that consumers of organic food are also health conscious in other areas of their life as they are less likely to harm their body with other unhealthy activities such as smoking.

\section{Consumption frequency related to lifestyle}

Some $75 \%$ of respondents stipulated that they do not follow a specific diet. Among the respondents that do follow a diet every day, consumption was the highest among vegetarian/vegan (4.76\%) respondents. Among vegetarian/vegan respondents the consumption frequency of organic food is high with all of them consuming organic at least once a month and most of them either on a daily or weekly basis. For other diets such as weight loss and related to sport/fitness the results are relatively in line with those that do not follow a specific diet, although the percentage that never consumes organic is relatively low.
Overall it can be concluded that people who do follow a specific diet are likely to consume organic food relatively often, however the difference between people that do not follow a diet programme is only really evident amongst those that follow a vegetarian/vegan diet.

In addition, physical exercise is another element directly related to pursuing a healthy way of living. Among all respondents, a total of $61.91 \%$ of consumers consume organic food on a daily or weekly basis. The data shows that $50 \%$ of total respondents both consume organic food on a daily or weekly basis as well as performing physical exercise on a daily or weekly basis. This suggests a strong correlation between high organic consumption frequency and high physical exercise frequency.

\section{4: RELATION BETWEEN DEMOGRAPHIC FACTORS AND ORGANIC CONSUMPTION FREQUENCY}

After analysing the potential link between lifestyle and consumption it is also fundamental to examine the interrelationship of socio-economic factors with consumer behaviour. This is to obtain a complete understanding of the market and to see if there are any behaviour differences between consumers from different personal backgrounds.

Of the total respondents, $21.43 \%$ consume organic food on a daily basis, $40.48 \%$ every week, $14.29 \%$ at least once a month, $14.29 \%$ less than once a month and $9.52 \%$ never consume organic food (Table 4). The majority of respondents fall into the 18 - 30 year old age category and are students.

TABLE 4: Consumption of organic food in relation to age

\begin{tabular}{|c|c|c|c|c|c|c|}
\hline \multicolumn{7}{|c|}{ Consumption of organic food } \\
\hline Demographics & $\begin{array}{c}\text { Every } \\
\text { day }\end{array}$ & $\begin{array}{c}\text { At least } \\
\text { once a } \\
\text { week }\end{array}$ & $\begin{array}{c}\text { At least once } \\
\text { a month }\end{array}$ & $\begin{array}{c}\text { Less than } \\
\text { once a } \\
\text { month }\end{array}$ & Never & $\begin{array}{c}\text { Grand } \\
\text { Total }\end{array}$ \\
\hline $\mathbf{1 8}$ - 30 years old & $11.90 \%$ & $34.52 \%$ & $13.10 \%$ & $14.29 \%$ & $9.52 \%$ & $83.33 \%$ \\
\hline $\mathbf{3 1}$ - 43 years old & $2.38 \%$ & $1.19 \%$ & $0.00 \%$ & $0.00 \%$ & $0.00 \%$ & $3.57 \%$ \\
\hline $\mathbf{4 4}$ - 56 years old & $3.57 \%$ & $4.76 \%$ & $0.00 \%$ & $0.00 \%$ & $0.00 \%$ & $8.33 \%$ \\
\hline $\mathbf{5 7}$ - 69 years old & $3.57 \%$ & $0.00 \%$ & $1.19 \%$ & $0.00 \%$ & $0.00 \%$ & $4.76 \%$ \\
\hline Grand Total & $\mathbf{2 1 . 4 3 \%}$ & $\mathbf{4 0 . 4 8 \%}$ & $\mathbf{1 4 . 2 9 \%}$ & $\mathbf{1 4 . 2 9} \%$ & $\mathbf{9 . 5 2 \%}$ & $\mathbf{1 0 0 . 0 0 \%}$ \\
\hline AGENCE BIO & $\mathbf{1 3 \%}$ & \multicolumn{6}{|c|}{$\mathbf{6 0 \%}$} & $\mathbf{1 7 \%}$ & $\mathbf{1 0 \%}$ & $\mathbf{1 0 0 . 0 0 \%}$ \\
\hline
\end{tabular}

When comparing these results to the national research results carried out by Agence BIO it can be stated that everyday consumption among this sample group is higher than the average with $21.43 \%$ of respondents opposed to $13 \%$.

\section{5: ASSUMPTIONS MADE FOR THE FUTURE OF ORGANIC AGRICULTURE AND CONSUMPTION}

The organic industry has developed considerably over the last two decades and it will be interesting to see for how long the continuous annual growth of the market can continue. So far, the annual sales figures in France do not seem to start slowing down yet. Even during the COVID-19 pandemic the industry shows a resistance against economic downturns.

Furthermore, from the primary research it has been observed that there is a real concern regarding climate change among consumers and that the vast majority has a positive attitude towards the consumption of organic products. In addition, consumers do not seem to find product availability or product range a barrier anymore in the current climate. Moreover, it was noted that more consumers than not leaned towards saying that organic products provide value for money.

\section{HYPOTHESES}

To provide context to the research, the seven hypotheses aforementioned will be tested. The primary research was specifically designed to verify these hypotheses.

Hypothesis $\mathrm{H} 1$ is supported. The three most important reasons indicated by respondents to purchase organic food were health benefits, absence of GMOs and environmental impact. Although the absence of GMOs was not specifically mentioned in the hypothesis it does both directly serve advantages for both health and environment. Furthermore, the difference in total scores between the first three product attributes and the other ones was quite significant. It can therefore be said that health benefits and the protection of the environment are the main reasons for purchasing organic food, with a side note that specifically the absence of GMOs seems to be the most important driver behind the benefits to both of these two attributes.

Hypothesis $\mathrm{H} 2$ is partly supported. An organic certification warranty was chosen least among respondents as reasons to purchase organic food. Furthermore, a lack of trust in organic products being actually organic and a lack of trust in certification logos were chosen as the third and fourth most important obstacles for selecting organic products. 
However, on the other hand, when asked if respondents would be more likely to purchase food products if it carries an organic label $39.29 \%$ agreed and $13.10 \%$ strongly agreed. Only $5.95 \%$ strongly disagreed along with $8.33 \%$ who disagreed and $33.33 \%$ who neither agreed nor disagreed. The results are therefore mixed. Consumers do not seem to look at organic labels as one of the main criteria in their purchase decision process, which could partly be because of a lack of trust. However, at the same time they respond to products more if they carry an organic label than if not.

Hypothesis H3 is partly supported. Price has emphatically been expressed as the main argument for not opting for an organic choice. Respondents cited having a higher income and prices being lower as the main two reasons in scenarios in which they would purchase more organic food products. A considerable $58.3 \%$ of respondents ranked either of these factors as their principal obstacle. On the contrary, out of the ten reasons that respondents could choose from, product availability in more stores and a wider product range ranked eighth and ninth respectively. This would indicate that consumers are content with the current availability of organic products both in the amount of points of sale where the products are sold as well as the variety of the product assortment in stores. Therefore, price is definitely the main reason for consumers not to purchase organic while low availability does not seem like a strong barrier in the current climate according to French consumers.

Hypothesis H4 is supported. There is a strong correlation between health consciousness, regular exercise and organic food consumption. It has already been stated that health benefits are the main reason for purchasing organic food among respondents. Furthermore, of the total respondents $61.91 \%$ consume organic food on a daily or weekly basis with $50 \%$ of total respondents both eating organic and performing physical exercise on a daily or weekly basis. This means that approximately 5 out of 6 consumers who regularly eat organic food also regularly exercise. In addition, a comparison was made in organic consumption frequency between smokers and nonsmokers. No smokers indicated to consume organic food on a daily basis whilst $23.44 \%$ of non-smokers were daily organic consumers. Also, on a weekly organic consumption basis the difference is clear, $34.38 \%$ of non-smokers consume organic food every week against $15 \%$ of smokers. It can therefore be said that this hypothesis is supported. Hypothesis H5 is partly supported. Nearly no respondents were not concerned by climate change at all, however it seems like some environmentally friendly practises are more integrated in the daily lifestyles than others. For instance, the data shows a clear positive relationship between people who recycle and the organic consumption frequency. Some $23.53 \%$ of people who recycle consume organic food every day as opposed to $12.5 \%$ who do not recycle. On a weekly basis, a higher representation is again in favour of those who recycle $(44.12 \%)$ against those who do not $(25 \%)$. It can thus be said that there is a strong relationship between these two factors. A weaker correlation was found between usage of public transport and organic consumption as there was no great disparity found in consumers that use public transport regularly and those that do not. Hence, this hypothesis can only be partly supported as consumers seem to integrate certain environmentally friendly practices. For instance, in the case of public transport usage practicality might be favoured.

Hypothesis $\mathrm{H} 6$ is partly supported. Approximately $70 \%$ of the sample group has an academic level equal to a master degree or higher and when comparing the consumption frequency to the national average it can be concluded that there is a positive relationship. Especially the everyday consumption is higher among the sample group compared to the data from Agence BIO. The primary research indicates there might be a positive correlation between consumption frequency and income as well, however the sample group did not consist of a sufficient amount of respondents with a high enough income to come to a decisive conclusion.

Hypothesis $\mathrm{H} 7$ is supported. Consumers have a positive attitude towards organic food in Brittany. On a five-point Likert scale $34.52 \%$ strongly agreed, $40.48 \%$ agreed, $19.0 \%$ neither agreed nor disagreed, $4.76 \%$ disagreed and only $1.19 \%$ strongly disagreed to having a positive attitude towards organic consumption. The amount of consumers that do not view organic consumption positively is relatively small whereas a considerable $75 \%$ of respondents do see it in a positive light. Consumers in Brittany are also very positive in their perception of there being a future for organic farming in their region, with $44.05 \%$ of respondents strongly agreeing to this statement and another $38.10 \%$ agreeing. However, the vast majority of consumers also acknowledge that authorities can do more to stimulate organic consumption.

\section{MAIN QUESTION: WHAT ARE THE MAIN DRIVERS IN CONSUMER BEHAVIOUR THAT INFLUENCE ORGANIC FOOD CONSUMPTION IN BRITTANY?}

The research has been centred around discovering the main drivers in consumer behaviour that influence organic food consumption in Brittany in both a positive and negative sense. The main question is answered based on the results of the primary research with support of the existing literature on the subject.

Product attributes that were most valued by consumers are health benefits, absence of GMOs and environmental impact. Especially health benefits and protection of the environment are factors that often come up as the principal reasons for organic consumption across research in various countries as well. This is also evident in the fact that consumers who regularly consume organic food also exercise on a regular basis and do not tend to be smokers. Moreover, people who recycle tend to be higher consumers of organic products and are concerned about climate change.

Absence of GMOs in such specific terms is cited less often; however, this production method is the driving force behind why organic products are firstly organic and secondly provide benefits for health and environment. Certification warranty logos and natural appearance of the products were indicated as the least important drivers in the decision-making process. On the contrary, price is seen as the primary obstacle for organic consumption. Organic food often comes with a price premium as the production input costs are higher than that of conventional agriculture. Consumers indicate that either higher incomes or lower product prices would alleviate this burden. Furthermore, a significant number of French consumers feel a lack of trust in products actually being organic. This could be solved by utilising organic certified labels; however, consumers show a lack of trust in these logos too. The least important hurdle for consumers is the product packaging not being environmentally friendly, which can be interpreted two ways. Either this is not seen as an important part of the purchase decision process or consumers are content with the current packaging being environmentally friendly and therefore do not put much emphasis on it. In addition, product range and product availability were seen as the other least prominent hurdles which would indicate that consumers are satisfied with the 
current access they have to organic products. There seems to be a positive correlation between the level of education and organic consumption. Additionally, consumers generally have a positive attitude towards organic products and see a future for organic consumption in Brittany.

Therefore, to conclude, factors having a positive effect on consumption of organic products are the health benefits that it provides along with the protection of the environment, mainly valued through the absence of GMOs. Also, availability of organic products does not seem to be a hurdle for French consumers as well as level of education being another positive driver of consumption. Elements that have a negative effect are price and lack of trust in products being organic.

\section{CONCLUSION AND RECOMMENDATIONS}

Brittany has a long history in agriculture and France has always been one of the countries at the forefront in the development of organic agriculture. In 2019, France was the third largest organic consumption market in the world behind the United States and Germany valued at $€ 11.93$ billion. This was a $13.5 \%$ increase compared to 2018, showing the massive growth the market is experiencing. Furthermore, the country has the second highest number of organic farms and second highest number of cultivated organic farmland in Europe.

Most organic products in France are sold through mass retail (55\%), followed by organic specialty stores $(28 \%)$, direct sales (11\%) and artisan traders (6\%). Organic products accounted for $6.1 \%$ of all food purchases in France in 2019. On average the yearly expenditure on organic products is $€ 178$ among French consumers. Moreover, the sales of organic products have continued to rise amidst the COVID-19 pandemic, demonstrating that the industry is fairly insensitive to crises.

Organic production is being supported by the French government as a long-term cornerstone of the agriculture industry. It has launched several initiatives such as farmers who convert conventional farmland to organic being eligible for financial funding, the launch of the $A B$ (Agriculture Biologique) organic label and sponsoring international events related to the development of organic production.

Conventional agricultural production in Brittany is principally concentrated on meat and dairy products while also being responsible for almost half of the national fishing sales. Additionally, the region has a significant output in vegetable cultivation as well. Brittany ranks eight out of the thirteen French regions in terms of certified organic farmland surface and sixth in number of organic farms. In terms of the usage of this organic surface, a large portion is dedicated to the production of forage $(74.9 \%)$, large crops $(16.17 \%)$, fruits and vegetables $(6.95 \%)$ among smaller category groups.

Not only the French government but also the European Union is a contributing factor to the organic industry with policy support measures, rural development campaigns and research. The European Union attempts to stimulate adoption of organic practises for mainly three reasons. In the first place, the global supply chains are being put under pressure with a growing world population. Especially in developing countries incomes will be rising with people increasingly searching for high quality food. Secondly, organic production practises can contribute in the fight against climate change. The European Union has set itself the goal of becoming the first climate neutral continent by 2050. In the third and last place, the European Union strives for balanced territorial development in its member states through increasing work opportunities and local economic advancement. One of the goals of the European Farm to Fork strategy is to achieve $25 \%$ of farmland being used for organic cultivation by 2030 .

According to Lancaster (1996), consumers are more interested in the benefits or characteristics which a good possesses than the physical product itself. Ten potentially beneficial product attributes typical of organic products had been outlined being absence of GMOs, animal welfare, certification warranty, environmental impact, expectation of better taste, health benefits, nutritional value, origin, natural appearance and fair compensation for farmers. In the primary research consumers were asked to rank them on a scale from 1 (most important) to 10 (least important). The attributes that scored highest among respondents in the primary research were health benefits, absence of GMOs and environmental impact. Attributes least chosen were certification warranty and products having a more natural appearance. The highest scoring attributes are in line with the existing academic literature across various countries and national research conducted by Agence BIO. The primary reason for the added health benefits gained from organic food is the absence of GMOs. Moreover, for fresh products such as fruit and vegetables that are locally organically produced the transport time will be shorter keeping the product fresher and preserving the nutritional value better. Research also proposes that a healthy diet does not only contribute to physical enhancements but also mental well-being. In organic production methods, GMOs are either completely absent or regulated to legal limits. Several potential negative health effects have been linked with the intake of pesticides such as an increase in the chances of getting prostate cancer, lung cancer, Parkinson's disease and Alzheimer. Climate change is a real global concern that affects the world in many ways. Organic production can contribute to lowering the $\mathrm{CO} 2$ output as it has a lower carbon footprint than conventional farming. In conventional agriculture practises more chemical pesticides and fertiliser are used as well as a higher usage of fossil fuels in the preparation of farm land. Aside from ranking the attributes most valued in the purchase decision for organic products, respondents were also asked to rank ten factors that would stimulate their organic consumption more. In other words, what the main obstacles are for opting for the organic option. Most significant hurdles were related to price, a lack of trust in products being actually organic and a lack of trust in organic certification labels. Another noteworthy factor that scored very low as a potential obstacle was availability, both in terms of the amount of stores that sell organic as well as the product range available in-store.

This would indicate drivers with the most strength in predicting organic consumption behaviour in Brittany are health benefits, absence of GMOs, environmental impact and price. Variables that have a relatively weak influence are certification warranties, natural appearance of the product and availability. It could mark the start of a broader understanding of the move towards a standardised consumer profile of frequent organic consumers in terms of benefits sought.

To gain a further understanding of organic consumer behaviour it should be explored whether there is a correlation between purchase decisions and lifestyle. A strong positive relationship was found between high consumption frequency and regular physical exercise. Furthermore, non-smokers are more likely to consume organic on a regular basis than smokers. The diet that translated the most into increased levels of organic consumption among respondents is a vegetarian/vegan diet. The results regarding people using public transport is inconclusive with there not being a distinct difference 
between those that consume organic frequently and those that do not. However, it was found that people who recycle their trash are more likely to opt for organic products more frequently. This relates to the level of concern for the environment and climate change of which the primary research shows that a higher level of concern converts into higher organic consumption frequencies.

In terms of socio-economic factors, it is found that consumers who profit from a greater level of education have a stronger inclination to purchase organic. This is emphasised by the primary research, with a sample group that consists of a large percentage of people who either are pursuing or in possession of a master degree who are consumers at a higher frequency than the national average statistics. The academic literature suggests a positive relation between income and organic consumption. This is highlighted by price being indicated as the most meaningful hurdle of purchasing organic products. Among respondents, organic consumption frequency seems slightly more prominent among males than females, which is not completely congruent with the existing literature. A possible explanation for this is that in existing research it is cited that females are more likely to buy organic as they are the main decision makers in every day shopping in a family. In the sample group, there is a relatively high representation of the age group 18 - 30 year olds. In this age group, many people have not arrived at the life phase yet that they have their own family. The future of organic consumption in the region of Brittany is perceived as being bright and will maintain a prominent place in the food industry for years to come. Nevertheless, the general feeling is that authorities can put in more effort to promote organic consumption.

The research proposes several recommendations that can contribute to the overall growth of the organic industry as a whole in Brittany:

(1) Marketing managers can with growing existing research on the subject differentiate and target subsegments of consumers' profiles appropriately to more effectively communicate their message and subsequently boost organic consumption. Various consumer groups might require various incentives to increase their organic consumption frequency with current existing consumers moving towards a more standardised consumer profile with similar benefits sought. However, socio-economic and lifestyle characteristics of consumers should not be underestimated and provide a valuable source of reaching potential consumers. The recommendation is to truly engage with consumers and communicate the benefits that justify the value for the price premium that organic products possess.

(2) Authorities can contribute more in terms of building trust in products actually being organic and the validity of organic certification labels, as this is still seen as a significant hurdle among consumers. Authorities are generally seen as a relatively trustworthy source of information and it is therefore encouraged to be more transparent in terms of product traceability. This information should be easy to find for consumers and organic certifications such as the $\mathrm{AB}$ label or the Euroleaf label can be promoted more with higher visibility to gain more trust from consumers.

(3) The most notable hurdle for purchasing organic, price is a more difficult obstacle to tackle. Large farms or producers will perhaps be able to push down prices through economies of scale. Similarly, close collaboration between local stakeholders might help to reduce input production costs. Another potential aid is government funding, which already exists in France, for those producers who convert their cultivation surface to organic. This can provide a higher incentive for farmers to make this conversion as it helps reduce operational risks. Furthermore, technological developments in production methods in the near future might make organic farming just as viable as conventional agriculture in terms of input costs.

(4) As aforementioned, current efforts by authorities to promote organic products seem not to connect sufficiently with consumers in Brittany. It will require acquiring research data on a local level to gain a deeper understanding of the consumer market and appropriately communicate its advantages to consumers. Furthermore, promotional campaigns can be realised by way of advertising or through for instance increasing the availability of organic products in public places such as school canteens. Moreover, the availability of information on benefits, production processes and traceability will contribute to consumer engagement. As indicated by Lampkin (1996) both a pull and push strategy can be used simultaneously to grow the organic sector as long as it is well calibrated.

Concerning limitations to the research, COVID-19 has impacted the way in which research is conducted as for instance it would be more challenging to obtain results in person from respondents. Furthermore, COVID-19 and seasonality might influence responses related to eating patterns. Moreover, time and budget constraints did not allow the research to be carried out on a larger scale. Furthermore, the research limits itself to the Brittany region and expanding the scope of the geographical location can be a potential extension for future research.

\section{REFERENCES}

[1] Agence Bio (n.d.). Elevage Bio: des normes élevées de bien-être animal. [online].

Available at: https://www.agencebio.org/wpcontent/uploads/2018/10/bien_etre_animal_en_bio .pdf [Accessed 24 July 2021].

[2] Bourdieu, P. (1979). La distinction. Critique sociale du jugement, Paris: Les editions de minuit.

[3] Dettmann, R.L. and Dimitri, C. (2010). Who's Buying Organic Vegetables? Demographic Characteristics of U.S. Consumers. Journal of Food Products Marketing, 16(1), 79-91.

[4] Dimitri, C. and Dettmann, R.L. (2012). Organic food consumers: what do we really know about them? British Food Journal, 114(8), 1157 - 1163.

[5] Direction Régionale de l'Alimentation, de l'Agriculture et de la F. de B.-S. officiel du service régional du ministère en charge de l'agriculture (2019). Agreste Bretagne Synthèse - La Bretagne agricole et alimentaire. [online] draaf.bretagne.agriculture.gouv.fr. Available at: https://draaf.bretagne.agriculture.gouv.fr/AgresteBretagne-Synthese-La [Accessed 8 July 2021].

[6] Gad Mohsen, M. and Dacko, S. (2013). An extension of the benefit segmentation base for the consumption of organic foods: A time perspective. Journal of Marketing Management, 29(15-16), 1701-1728. Available at: https://www.tandfonline.com/doi/full/10.1080/02 67257X.2013.800896 [Accessed 16 August 2021]. 
[7] Götze, F. (2019). Demand for organic food in Switzerland. Available at: https://www.researchgate.net/publication/340000 274_Demand_for_organic_food_in_Switzerland [Accessed 3 August 2021].

[8] Kotler, P., Wong, V., Saunders, J. and Armstrong, G. (2005). Principles of Marketing (4th ed.). London: Pearson Education Limited.

[9] Lampkin, N. (1996). Organic farming and agricultural policy in Western Europe. [online] Available at: https://www.researchgate.net/publication/287656 335_Organic_farming_and_agricultural_policy_in_We stern_Europe [Accessed 28 September 2021].

[10] Lancaster, K.J. (1966). A New Approach to Consumer Theory. Journal of Political Economy, [online] 74(2), 132-157. Available at: https://www.jstor.org/stable/1828835 [Accessed 19 July 2021].

[11] Latacz-Lohmann, U., Foster, C. (1997). From "niche" to "mainstream" - strategies for marketing organic food in Germany and the UK. Available at: https://www.emerald.com/insight/content/doi/10. 1108/00070709710188336/full/html [Accessed 16 August 2021].

[12] Li, J., Zepeda, L. and Gould, B.W. (2007). The Demand for Organic Food in the U.S.: An Empirical Assessment. Journal of Food Distribution Research, 38(3), 54-69.

[13] Maigné, É., Monier-Dilhan , S. and Poméon, T. (2017). Impact of the consumer's environment on the demand for organic food in France. Journal of Organics, 4(1), 3-20.

[14] Magnusson, M.K., Arvola, A., Hursti, U-K. K. and Sjödén, P-O. (2001). Attitudes towards organic foods among Swedish consumers. British Food Journal, 103(3), 209-227.

[15] Marty, L., de Lauzon-Guillain, B., Labesse,. M., Nicklaus, S. (2021). Food choice motives and the nutritional quality of diet during the COVID-19 lockdown in France. Appetite, [online] 157, 105005. Available at: https://www.sciencedirect.com/science/article/pii /S0195666320316275 [Accessed 25 Nov. 2020]
[16] Nunes, F., Madureira, T. and Veiga, J. (2021). The Organic Food Choice Pattern: Are Organic Consumers Becoming More Alike? Foods, 10(5), 983. Available at:

http://dx.doi.org/10.3390/foods10050983 [Accessed 3 August 2021]

[17] Ozguven, N. (2012). Organic Foods Motivations Factors for Consumers. Procedia - Social and Behavioral Sciences, 62, 661-665. Available at: https://www.researchgate.net/publication/271583 966_Organic_Foods_Motivations_Factors_for_Consu mers [Accessed 16 July 2021].

[18] Statista. (n.d.). Worldwide sales of organic foods, 2018. [online] Available at:

https://www.statista.com/statistics/273090/world wide-sales-of-organic-foods-since-1999/ [Accessed 5 July 2021].

[19] Shafie, F.A. and Rennie, D. (2012). Consumer Perceptions Towards Organic Food. Procedia - Social and Behavioral Sciences, 49, 360-367. Available at: https://www.researchgate.net/publication/257716 052_Consumer_Perceptions_Towards_Organic_Food [Accessed 13 August 2021]

[20] Wier, M., O’Doherty Jensen, K., Andersen, L.M. and Millock, K. (2008). The character of demand in mature organic food markets: Great Britain and Denmark compared. Food Policy, 33(5), 406-421. Available at: http://dx.doi.org/10.1016/j.foodpol.2008.01.002 [Accessed 19 July 2021]

[21] Zepeda, L. and Li., J. (2007). Characteristics of Organic Food Shoppers. Journal of Agriculture and Applied Economics, 39(1), 17-28.

[22] Zhang, F., Huang,. C. L., Lin,. B. (2006). Modeling fresh organic produce consumption: a generalized doublehurdle model approach. Available at:

https://www.researchgate.net/publication/235157 14_Modeling_fresh_organic_produce_consumption_a _generalized_double-hurdle_model_approach [Accessed 13 August 2021]. 